\section{Results}

The patient's and control bone marrow samples grew normally in the absence of antimalarial drugs. No antimalarial had any effect on normal marrow growth. Proguanil, pyrimethamine, and quinine had no effect on growth of the patient's marrow. Amodiaquine, chloroquine (a related 4aminoquinoline), and sulfadoxine, however, produced a dose dependent reduction in the number of colonies (figure).

\section{Discussion}

These results suggest that amodiaquine was responsible for the agranulocytosis since growth of colonies of granulocytes and macrophages was sensitive to this agent and recovery ensued on stopping the amodiaquine alone. Another patient with agranulocytosis had shown in vitro inhibition of growth of granulocytes and macrophages by amodiaquine early in the recovery phase.' A similar in vitro inhibitory effect was seen in a case of agranulocytosis induced by quinine. ${ }^{3} \mathrm{~A}$ specific effect on marrow colony growth is suggested, separate from any systemic abnormality of drug handling.

Our patient wished to know if she could take any medication to enable her to travel safely to areas where malaria was endemic. Clearly, $\underline{T}$ amodiaquine, chloroquine, and sulfadoxine were to be avoided. Though we could not be certain that the other drugs tested would be $\stackrel{\AA}{\propto}$ safe, our results suggested that in vitro marrow culture may have important predictive value in some cases of drug induced agranulo- $\widehat{\widehat{O}}$ cytosis.

We thank Dr J B Wood, of Hereford County Hospital, for referring the patient and for permission to report the case. We also thank Imperial Chemical Industries PLC for supplying proguanil hydrochloride and chloroquine $\varrho$

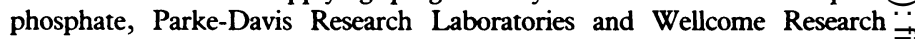
Laboratories for supplying amodiaquine hydrochloride, and Roche Products Ltd for supplying pyrimethamine and sulfadoxine, all in pure drug form.

\section{References} Vincent PC. Amodiaquine-induced agranulocytosis: toxic effect of amodiaquine in bone marrow cultures in vitro. Br Med f 1973;i:458-60.

2 Pike BL, Robinson WA. Human bone marrow colony growth in agar-gel. $f$ Cell Physiol 1970;76:77-84. $\vec{\circ}$ 3 Sutherland R, Vincent PC, Raik E, Burgess K. Quinine-induced agranulocytosis: toxic effect of quinine bisulphate on bone marrow cultures in vitro. $\mathrm{Br}$ Med $\mathcal{f} 1977$;i:605-7.

(Accepted 4 February 1986)

\title{
An early marker of fetal infection after primary cytomegalovirus infection in pregnancy
}

\section{HAROLD STERN, GILLIAN HANNINGTON, JAMES BOOTH, DEBORAH MONCRIEFF}

\begin{abstract}
Fourteen patients with primary cytomegalovirus infection diagnosed by serological screening at antenatal attendances were examined for their responses in the lymphocyte transformation test against cytomegalovirus. Tests were done during pregnancy, shortly after the diagnosis of primary infection.

Eight women showed positive lymphocyte transformation responses and gave birth to uninfected babies. Six showed negative responses and four of the babies were born congenitally infected. Cellular immunity therefore plays a part in preventing intrauterine transmission of cytomegalovirus, and its depression after primary infection in the mother during pregnancy may be used as an early marker of fetal infection.
\end{abstract}

\section{Introduction}

Cytomegalovirus is the most common known cause of congenital infection in man and is as important, or more important, than rubella as a cause of handicap. In the United Kingdom $40-50 \%$ of women of childbearing age are seronegative and rather fewer than $1 \%$ of these undergo primary infection at some time during pregnancy.$^{1.3}$ Following primary infection transmission of virus to

\footnotetext{
Departments of Virology and Obstetrics, St George's Hospital Medical School, London SW17 0RE

HAROLD STERN, FRCPATH, professor of virology

GILLIAN HANNINGTON, PHD, research fellow in virology

JAMES BOOTH, PHD, MRCPATH, senior lecturer in virology

DEBORAH MONCRIEFF, MRCOG, senior registrar in obstetrics

Correspondence to: Professor Stern
}

the fetus occurs in $25-50 \%$ of cases. ${ }^{14}$ Only $10-14 \%$ of the infected ${ }^{\infty}$ fetuses, however, suffer important sequelae, usually neurological damage or sensorineural deafness. ${ }^{5.7}$ The overall risk of a baby being born with congenital abnormality after primary infection in the mother is therefore relatively low, probably $5 \%$ or less. Hence it has been advocated that, as there is no means of identifying the $\frac{\circ}{\Phi}$ pregnancies most at risk of resulting in a handicapped baby, neither $\varrho$ screening for primary infection nor termination, as offered for $\overrightarrow{\overrightarrow{0}}$ rubella, is justified.$^{89}$

Women who have given birth to babies congenitally infected with cytomegalovirus have been found to have depressed cell mediated immunity to cytomegalovirus, demonstrable by the lymphocyte transformation test, ${ }^{10}$ with a tendency to greater depression in the mothers who had given birth to infants with abnormalities. ${ }^{12}$ All $;$ these studies, however, were carried out only after delivery, usually many months later. This study was undertaken to see whether $\delta$ measurement of lymphocyte transformation response during pregnancy, at the time of occurrence of the primary infection, could 9 predict the likelihood of intrauterine infection. Such information would be invaluable in clinical management.

\section{Patients and methods}

Since July 1982 women attending the antenatal booking clinics of St $\bar{O}$ George's Hospital and the South London Hospital have been routinely 0 screened for serum cytomegalovirus specific IgG by indirect enzyme linked $\stackrel{D}{\Phi}$ immunosorbent assay. ${ }^{13}$ Positive serum samples were re-examined for $\stackrel{\mathbb{P}}{+}$ cytomegalovirus specific IgM, also by indirect enzyme linked immuno- 0 sorbent assay, to determine whether infection had occurred within the preceding two to three months (see below). Most of the women were first $\overrightarrow{\mathbb{D}}$ seen at about 12 weeks' gestation. Women who were seronegative were re- $\frac{?}{\mathbb{P}}$ examined at intervals during the pregnancy for seroconversion. When $\stackrel{\mathbb{Q}}{\varrho}$ primary infection was diagnosed, whether by seroconversion or by the presence of cytomegalovirus specific $\operatorname{IgM}$, the patient was recalled as soon as $\varnothing$ possible and a lymphocyte transformation test carried out; this was repeated $\frac{0}{0}$ at further intervals during pregnancy and again at term. All women enrolled in the investigation were made fully aware of its nature, and follow up examinations were undertaken only with their consent; about a third of the 
seronegative women attending the booking clinics agreed to cooperate. The consultant obstetricians were responsible for counselling those women in whom primary infection was diagnosed; all 14 such women in the study desired the pregnancy to continue to term.

Antigens-Cytomegalovirus (strain AD169) and control antigens were prepared in MRC-5 diploid human fibroblast tissue cultures as described. ${ }^{13}$

Lymphocyte transformation test-Mononuclear cells were isolated by layering the patient's fresh heparinised whole blood on to Ficoll Paque (Pharmacia Ltd) and spinning at $2000 \mathrm{rpm}$ for 30 minutes. The cells were washed three times with Roswell Park Memorial Institute (RPMI) 1640 medium (Flow Laboratories) containing 1\% preservative free heparin and resuspended in RPMI 1640 medium with $15 \%$ autologous plasma at a concentration of $1 \times 10^{6}$ viable cells $/ l$. The test was carried out in tissue culture grade microtitre plates (Sterilin M29 ARTL); $0.2 \mathrm{ml}$ cell suspension was dispensed into each well. Ten microlitre samples of cytomegalovirus antigen (in fourfold dilutions from one in four to one in 4096), control antigen (diluted one in four), $1 \%$ phytohaemagglutinin, or medium only were each added to quadruplicate wells. The phytohaemagglutinin cultures were incubated for three days and the virus cultures for five days at $37^{\circ} \mathrm{C}$ in $5 \% \mathrm{CO}_{2}$ before adding $10 \mu \mathrm{l}$ samples of tritiated thymidine $(2 \mathrm{Ci} / \mathrm{mm})$ for a final 18-24 hours of incubation. Cells were harvested automatically with a Dynatech Multimash on to glass fibre paper and the uptake of radioactive thymidine measured as cpm in an LKB 1215 RackBeta II liquid scintillation counter. Results from quadruplicate wells were expressed as a stimulation index, calculated by dividing the mean reading from the virus stimulated cultures or the phytohaemagglutinin stimulated cultures by the mean reading from the relevant control cultures. The stimulation index was regarded as positive when the radioactive counts with the virus antigen differed significantly from those with the control antigen (Student's $t$ test).

Virus isolation-Urine, throat washings, and cervical swabs were collected from each woman in whom primary cytomegalovirus infection had been diagnosed whenever blood was taken for a lymphocyte transformation test. A urine specimen was collected from the baby within the first two weeks of life, usually within a day or two of birth. Specimens were taken directly into transport medium and inoculated within one to two hours on to MRC-5 tissue cultures; cultures were examined for cytopathic effects over 21 days.

\section{Results}

\section{WOMEN WITH PRIMARY CYTOMEGALOVIRUS INFECTION}

Screening for cytomegalovirus IgG antibody was carried out on 8815 women at their first antenatal attendance; results were positive in 5852 women $(66 \%)$, and these were then examined for $\operatorname{IgM}$ antibody. Of the 2963 women who were seronegative, most were receiving shared care, making subsequent visits to their general practitioners rather than to the hospital, and only 553 could be persuaded to undergo continuing serological tests during the rest of the pregnancy.

Primary cytomegalovirus infection was diagnosed in 14 pregnant women -in 10 by the presence of cytomegalovirus specific IgM at their booking attendance and in four by seroconversion. Specific IgM developed in all 14 cases and in the seroconverters persisted for at least eight weeks. Primary infection occurred in all trimesters of pregnancy (table I). All the infections were apparently subclinical.

TABLE I-Trimester of pregnancy when primary cytomegalovirus infection was diagnosed (14 cases)

\begin{tabular}{lccccc}
\hline \multirow{2}{*}{$\begin{array}{l}\text { Primary cytomegalovirus infection } \\
\text { diagnosed by: }\end{array}$} & $\begin{array}{c}\text { No of } \\
\text { cases }\end{array}$ & \multicolumn{4}{c}{ Trimester in which diagnosis made } \\
\cline { 3 - 6 } $\begin{array}{l}\text { Cytomegalovirus IgM at booking } \\
\text { Seroconversion }\end{array}$ & 10 & 2 & 2nd & 3 rd \\
\hline
\end{tabular}

\section{LYMPHOCYTE TRANSFORMATION RESPONSES}

At the first lymphocyte transformation test after diagnosis of primary infection six women gave a negative response with the cytomegalovirus antigen and eight a positive response (table II). There was no obvious correlation between the occurrence of a positive or negative response and the trimester of pregnancy when primary infection occurred. Among the six women with negative responses four were diagnosed as having primary infections by finding cytomegalovirus specific IgM at booking and two by seroconversion. Five of them were primigravidas aged 17-19 years and one was aged 35 and in her third pregnancy. In five women the negative
TABLE II-Lymphocyte transformation response and virus excretion in 14 pregnant women with primary cytomegalovirus infection

\begin{tabular}{lccc}
\hline $\begin{array}{c}\text { Primary cytomegalovirus infection } \\
\text { diagnosed by: }\end{array}$ & $\begin{array}{l}\text { Lymphocyte transformation } \\
\text { response to cytomegalovirus }\end{array}$ & $\begin{array}{c}\text { No of } \\
\text { cases }\end{array}$ & $\begin{array}{c}\text { No } \\
\text { excreting virus }\end{array}$ \\
\hline Cytomegalovirus IgM at booking & $\left\{\begin{array}{l}+ \\
-\end{array}\right.$ & 6 & 2 \\
Seroconversion & $\left\{\begin{array}{l}+ \\
-\end{array}\right.$ & 2 & 2 \\
\end{tabular}

lymphocyte transformation response persisted to term, but in one (aged 18) a negative response at 27 weeks became positive at 35 weeks, when delivery took place.

Among the eight women with a positive lymphocyte transformation response six were diagnosed by finding specific $\operatorname{IgM}$ at first attendance and two by seroconversion. Three were primigravidas aged 21-33 years (mean 25) and the others multigravidas aged 21-33 years (mean 28). In all eight cases the positive responses persisted to term.

All 14 women responded positively in the lymphocyte transformation test to stimulation with phytohaemagglutinin and there was no significant difference in the magnitude of the phytohaemagglutinin responses between the cytomegalovirus positive and cytomegalovirus negative lymphocyte transformation responders.

\section{VIRUS EXCRETION IN THE MOTHERS}

Cytomegalovirus was isolated from only six of the 14 primary infections; all four women who had seroconverted excreted virus, but only two of the 10 women who had been diagnosed by finding cytomegalovirus specific IgM at booking did so (table II). Among the four seroconverters two showed a positive lymphocyte transformation response and two a negative lymphocyte transformation response to cytomegalovirus. On the other hand, among the 10 women diagnosed at booking the only two virus excretors both gave negative responses in the lymphocyte transformation test. Among the seroconverters virus was isolated from multiple sites, usually urine and cervix; among the other two excretors virus was isolated from urine only.

TABLE III-Incidence of congenital infection in babies born to 14 women with positive or negative lymphocyte transformation responses after primary cytomegalovirus infection during pregnancy

\begin{tabular}{ccc}
\hline No of women & $\begin{array}{c}\text { Lymphocyte transformation response to } \\
\text { cytomegalovirus }\end{array}$ & $\begin{array}{c}\text { No of congenitally infected } \\
\text { babies }\end{array}$ \\
\hline 8 & + & 4 \\
6 & - & 4
\end{tabular}

\section{CONGENITAL INFECTIONS}

All 14 pregnancies resulted in apparently healthy babies. Only four of the 14 babies (29\%) excreted cytomegalovirus in the urine at birth, and they were born to mothers who gave a negative lymphocyte transformation response to cytomegalovirus at the time of the primary infection (table III). The other two women who had shown negative lymphocyte transformation responses but gave birth to uninfected babies underwent primary infection during the first (six weeks) and third (39 weeks) trimesters, respectively. The four congenitally infected babies were born to mothers in whom diagnosis of primary infection was made during the first, second, third, and third trimesters, respectively. None of the eight women with a positive lymphocyte transformation response gave birth to congenitally infected babies.

The correlation between a negative lymphocyte transformation response to cytomegalovirus after primary infection in pregnancy and congenital infection in the baby was significant $(p=0.03)$. None of the 14 babies showed any developmental abnormalities after six to 12 months of follow up.

\section{Discussion}

The number of patients in this report is small and the study is continuing. Nevertheless, the results so far suggest that cell mediated immunity to cytomegalovirus plays a crucial part in determining whether or not the virus will be transmitted to the fetus 
after primary infection in pregnancy. Six women failed to develop a cell mediated immunity response to cytomegalovirus, of whom four gave birth to congenitally infected babies. In the other two women primary infection was diagnosed either very early in pregnancy (at six weeks), so that the infection may actually have occurred before conception, or very late (one week before delivery), so that there may not have been time for intrauterine transmission to occur. By contrast, none of the eight women who did develop a cell mediated immunity response to cytomegalovirus infected her baby. The response to phytohaemagglutinin was similar in all the women, suggesting that, as in cytomegalovirus seropositive women who subsequently become pregnant, ${ }^{14}$ the loss of cell mediated immunity response after primary infection is not generalised but is cytomegalovirus specific.

Women under 20 were more likely not to develop a cell mediated immunity response to primary infection. Thus five of the six women with negative lymphocyte transformation responses were aged 17-19 years, whereas the eight women with positive responses were aged 21-33. This may account for observations that mothers of babies congenitally infected with cytomegalovirus tend to be younger than the average maternal age, ${ }^{15}$ though why they should be less responsive in their cellular immunity is not immediately apparent. On the other hand, the cell mediated immunity response, as determined by the lymphocyte transformation test, did not appear to be influenced by the stage of pregnancy when primary infection occurred. Consequently, as recognised previously, ${ }^{12716}$ fetal infection may occur at any stage of pregnancy.

Whether or not virus was isolated from the women may have depended to some extent on how early in the infection specimens were obtained. Thus virus was isolated from all four women who seroconverted, and from multiple sites, perhaps because it was possible to collect specimens soon after primary infection occurred; on the other hand, only two of the 10 women in whom primary infection was diagnosed by finding cytomegalovirus specific $\operatorname{IgM}$ at the initial booking attendance had detectable virus excretion, and only in the urine, perhaps because a longer interval had elapsed between the actual infection and its diagnosis. Though virus excretion after primary cytomegalovirus infection in pregnancy may therefore often be transient, there was evidence that absence of a lymphocyte transformation response might result in a more prolonged excretion; none of the six women diagnosed by finding specific $\operatorname{IgM}$ at booking and who had a positive lymphocyte transformation response excreted virus, while two of the four women diagnosed in this way and who had a negative lymphocyte transformation response did excrete virus. There is therefore support for the observation that women who shed high titres of cytomegalovirus during pregnancy are at increased risk of being delivered of a congenitally infected baby. ${ }^{17}$

Our results suggest that the lymphocyte transformation test may be useful for predicting the likelihood of fetal infection when primary cytomegalovirus infection has been diagnosed in the mother during pregnancy. While larger numbers of cases are required to confirm these preliminary findings, there may now be a case for reversing previous recommendations on the value of screening for primary cytomegalovirus infection in pregnancy, particularly if quantitative measurements of cell mediated immunity can further differentiate between fetal infection and fetal damage.

We thank the consultants of the departments of obstetrics and gynaecology (namely, Professor G V N Chamberlain, Miss M Stokes, Mrs U B Lloyd, Mrs T R Varma, Mr A G Amias, and Mr J M F Pearce) for permission to screen their patients and their generous help in counselling the patients and collecting specimens, and Dr N McIntosh for his clinical follow up of the babies. We are also grateful to the various nursing staff for their willing cooperation, to Dr Primrose Watkins for help in collecting blood specimens, and to Miss Yvonne Tryhorn for carrying out the virus isolation procedures. We are indebted to the Mental Health Foundation for its generous support for this study.

\section{References}

1 Stern $\mathrm{H}$, Tucker SM. Prospective study of cytomegalovirus infection in pregnancy. $\mathrm{Br} \mathrm{Med} \mathfrak{J}$ 1973;ii:268-70.

2 Griffiths PD, Campbell-Benzie A, Heath RB. A prospective study of primary cytomegalovirus infection in pregnant women. Br f Obstet Gynaecol 1980;87:308-14.

3 Grant S, Edmond E, Syme J. A prospective study of cytomegalovirus infection in pregnancy. I: laboratory evidence of congenital infection following maternal primary and reactivated laboratory evidence of congenital infection
infection. fournal of Infection 1981;3:24-31.

4 Ahlfors K, Ivarsson S-A, Harris S, et al. Congenital cytomegalovirus infection and disease in Sweden and the relative importance of primary and secondary maternal infection. Scand $\mathcal{f}$ Infect Dis 1984;16:129-37.

5 Stern $\mathrm{H}$. Cytomegalovirus infection in the neonate and its prevention. Postgrad Med $\mathrm{J}$ 1977;53:588-91.

6 Stagno J, Pass RF, Dworsky ME, et al. Congenital cytomegalovirus infection: the relative importance of primary and recurrent maternal infection. N Engl f Med 1982;306:945-9.

7 Preece PM, Pearl KN, Peckham CS. Congenital cytomegalovirus infection. Arch Dis Child 1984;59:1120-6.

8 Anonymous. Congenital cytomegalovirus infection [Editorial]. Lancet 1983;i:801-2.

9 Anonymous. Cytomegalovirus infections in pregnancy [Editorial]. Br 7 Obstet Gynaecol 1984;91:305-6.

10 Gehrz RC, Marker SC, Knorr SO, Kolls JM, Balfour HH. Specific cell-mediated immune defect in active cytomegalovirus infection of young children and their mothers. Lancet 1977;ii:844-7.

11 Starr SE, Tolpin MD, Friedman HM, Paucker K, Plotkin SA. Impaired cellular immunity to cytomegalovirus in congenitally infected children and their mothers. F Infect Dis 1979;140: 500-5.

12 Reynolds DW, Dean PH, Pass RF, Alford CA. Specific cell-mediated immunity in children with congenital and neonatal cytomegalovirus infection and their mothers. $\mathcal{J}$ Infect Dis 1979;140 493-9.

13 Booth JC, Hannington G, Aziz TAG, Stern H. Comparison of enzyme-linked immunosorbent assay (ELISA) technique and complement-fixation test for estimation of cytomegalovirus IgG antibody. I Clin Pathol 1979;32:122-7.

14 Gehrz RC, Christianson WR, Linner KM, Conroy MM, McCue SA, Balfour HH. A longitudinal analysis of lymphocyte proliferative responses to mitogens and antigens during human analysis of lymphocyte proliferative responses

15 Starr JG, Bart RD, Gold E. Inapparent congenital cytomegalovirus infection. $N$ Engl f Med 1970;282:1075-8.

16 Monif GRG, Egan EA, Held B, Eltzman DV. The correlation of maternal cytomegalovirus infection during varying stages of gestation with neonatal involvement. $\mathcal{J}$ Pediatr 1972;80: 17-20.

17 Nankervis GA, Kumar ML, Cox FE, Gold E. A prospective study of maternal cytomegalovirus infection and its effect on the fetus. Am F Obstet Gynecol 1984;149:435-40.

(Accepted 13 December 1985)

\section{YEARS AGO}

The unmanly and unsportsmanlike practice of catching fish out of season cannot be too strongly reprehended. There is no doubt about its being illegal; the Freshwater Fisheries Act, 1878, and the Norfolk and Suffolk Fisheries Act of the year before ( 41 and 42 Vict. cap. 39,40 ; and 41 Vict. cap. 98) plainly forbidding it; nor can the public plead ignorance, as notices have been freely shown by the Fisheries Department and the Home office, giving particulars of the provisions by law relating to the "close time," "sale," etc., of freshwater fish. Yet, between October 2nd and February 1st, trout and char are taken wholesale, for the most part with gaffs, and snares, and spears, and all kinds of poaching implements; and even the roe of the fish thus cruelly taken, is used as bait for taking others. During the "close time" for freshwater non-migratory fish other than pollan, trout and char (that is, from the middle of March to the middle of June), very little mercy is shown. Even that atrocious instrument, dynamite, is now used by the nightpoachers. Of course, anything we could say as to the ruinous wastefulness of catching fish during a "close time" is likely to weigh very little with the offenders who do this dirty work; but these, after all, are not the chief culprits. If there were no market for fish out of season, very few would be caught. To the dealers who traffic in such goods, and to the public who buy, we appeal. They are themselves doing an illegal act, and inciting others to break the law: they are acting inhumanly to the spawning fish, they are doing their best to deprive the poor altogether of a much esteemed and economic food. Perhaps, however, there is an argument that may be more convincing even than these-it is, that fish out of season are unwholesome. A fish in prime order should be rather short in the body, small in the head, thick in the shoulders, and (as Frank Buckland says) should have a "grand prize-pig-like back;" it should be firm-fleshed throughout, and the rigor mortis should be well marked. Anyone who has seen a fish taken just before or immediately after spawning, will know how far it falls short of this description. Such fish have not the normal flavour, and soon decompose; and, even if eaten quite fresh, are likely to produce symptoms closely resembling those produced by sausage-poisoning, epigastric pain, diarrhoea, retching, and sense of heat in the throat. Fortunately for those fond of fish, the different species have different seasons; thus, there is always some kind of fish in good condition, and there is no excuse for a practice that is unlawful, cruel, wasteful, and unsanitary. (British Medical fournal 1886;i:412.) 